\title{
Review \\ Clinical review: The role of the intensive care physician in mass casualty incidents: planning, organisation, and leadership
}

Peter J Shirley and Gerlinde Mandersloot

Royal London Hospital, Whitechapel, London, E1 1BB, UK

Corresponding author: Peter Shirley, Peter.Shirley@bartsandthelondon.nhs.uk

Published: 14 May 2008

This article is online at http://ccforum.com/content/12/3/214

(c) 2008 BioMed Central Ltd
Critical Care 2008, 12:214 (doi:10.1186/cc6876)

\begin{abstract}
There is a long-standing, broad assumption that hospitals will ably receive and efficiently provide comprehensive care to victims following a mass casualty event. Unfortunately, the majority of medical major incident plans are insufficiently focused on strategies and procedures that extend beyond the pre-hospital and early-hospital phases of care. Recent events underscore two important lessons: (a) the role of intensive care specialists extends well beyond the intensive care unit during such events, and (b) non-intensive care hospital personnel must have the ability to provide basic critical care. The bombing of the London transport network, while highlighting some good practices in our major incident planning, also exposed weaknesses already described by others. Whilst this paper uses the events of the 7 July 2005 as its point of reference, the lessons learned and the changes incorporated in our planning have generic applications to mass casualty events. In the UK, the Department of Health convened an expert symposium in June 2007 to identify lessons learned from 7 July 2005 and disseminate them for the benefit of the wider medical community. The experiences of clinicians from critical care units in London made a large contribution to this process and are discussed in this paper.
\end{abstract}

\section{Introduction}

7 July 2005 witnessed the first suicide bombing on the UK mainland, targeting the public in London. The multiple bomb explosions on the London Underground and bus transport system resulted in the biggest mass casualty incident in the UK since the Second World War (52 dead and more than 700 injured). This was preceded by a similar attack in Madrid in 2004 and followed by an attack in Mumbai in 2006, also targeting transport infrastructure.

The Royal London Hospital (RLH) is a teaching hospital and major trauma centre, with a 16-bed intensive care unit (ICU), supplemented by a 6-bed surgical high-dependency unit (HDU). On the day of the bombings, 194 casualties were seen at the hospital, of whom 27 were admitted; 7 casualties requiring ventilatory support were admitted to the ICU and the remainder to the trauma ward and HDU. All of the intensive care patients had been triaged directly to the operating theatre to undergo major surgery, including limb amputations, thoracotomy, laparotomy, and craniotomy. After surgery, the patients were transferred to the ICU, from which further assessments (including secondary and tertiary trauma surveys) were organised. The bombing of the London transport network, while highlighting some good practices in our major incident planning, also exposed weaknesses already described by others $[1,2]$.

It seems clear to us, in reflecting on our response to the events and the ensuing critical care requirements, that intensivists should be intimately involved in disaster planning and in the initial stages of the response to any major incident. This paper, based in part on our participation with the UK Department of Health expert symposium convened during June 2007, will discuss how this might occur and at what stages of these processes.

\section{Intensive care medical response: 7 July 2005 Initial intensive care unit physician response}

Five senior intensive care doctors were in the hospital at the time the major incident was declared, and two more subsequently were able to attend. (Of this total, six were anaesthetists and one a physician.) None of these senior medical staff was notified via the paging system or mobile phone network that a major incident was declared. Runners were more effective in disseminating this information. As patients were triaged to the theatre, there was ICU consultant and registrar input in the resuscitation room and also in the operating theatre complex. Although this separated the staff, it did mean there was regular communication and early management regarding the progress of patients who were ultimately admitted to the ICU. 


\section{Intensive care unit command and control}

The senior nursing office area in the ICU was set up as the ICU coordination centre, with the ICU matron taking a lead administrative role in organising and dispatching runners to get updates, particularly from the operating theatre. A local supermarket provided free food for the ICU staff during the afternoon of 7 July. As the day progressed, one ICU registrar was assigned as a dedicated clerk, working at a computer terminal producing an updateable worksheet on each individual patient with details of injury pattern, investigations, results, and completed and planned surgery. This was the singularly most useful effort and made the planning and organisation of subsequent care for each patient more streamlined.

\section{Intensive care unit patient flow through the hospital}

Of the seven patients who were admitted to the ICU, all were post-operative and sedated and ventilated, and their triage had taken place in the resuscitation room by a senior surgeon. As a result, no patient admitted to the ICU had fully completed secondary surveys and several had missing radiology. Three ventilated patients were identified as being fit for transfer and were taken to other hospitals in Northeast London with capacity expanded by the cancellation of major elective surgical procedures. Four non-ventilated patients were transferred to other hospital beds at the RLH. All HDU beds except one were cleared and patients moved to ward care. The five empty HDU beds were set up as emergency ICU beds, with an additional four satellite beds set up in the operating theatre recovery area. This work was done mainly by the critical care outreach team (CCOT), but during the event all of the intensive care patients were accommodated within the physical space of the ICU.

All of these patients required ongoing critical care support for an extended period of time (beyond the average ICU length of stay) and all required repeated surgery. Over 180 hours of additional theatre time were required over the following 3 weeks. Hospital length of stay was variable, and outpatient follow-up for physical, as well as psychological, support is still ongoing [3].

The successful outcome of the vast majority of patients admitted to the RLH ICU on 7 July was multi-factorial and included the relatively low number of seriously injured casualties and the ability to contain them all within the ICU. This enabled effective teamwork by clinicians from many specialties who already had extensive experience dealing with poly-trauma patients. At the time, however, this situation generated many organisational and clinical learning points, which have been incorporated into future training for medical and nursing staff in the ICU, particularly in relation to flu pandemic planning.

Most major incident planning concentrates on the first 6 hours, when most patients will not yet have reached the ICU. There is little emphasis on the impact of this phase of care from the ICU point of view or, in fact, on what is now termed 'the prolonged-care phase' following ICU admission.

\section{The role of critical care in pre-incident planning \\ Why should intensivists become involved in disaster planning?}

It may seem to some that events on a large scale are the remit of someone else's planning responsibility. Beyond planning, many/most assume that the government and/or the military will provide the necessary response capabilities. These misconceptions can easily lead to three forms of denial: (a) it will not happen here, (b) it will not happen to me, or (c) someone else will take care of the problem.

Israeli physicians have shown that $4.7 \%$ of patients presenting to the emergency department after terrorist bombings require intensive care. In their experience, the greatest use of ICU personnel and equipment occurs during the resuscitation and resource allocation phases of the response to the incident; their presumption is that around $70 \%$ of the patients admitted to the ICU would require mechanical ventilation [4].

Often, while the initial emphasis is on expanding bed capacity, scant attention is paid to the longer-term critical care needs of these patients. Intensivists not only bring a multi-disciplinary approach to planning, but also have the dayto-day clinical experience in dealing with the sickest patients in hospital [5]. In addition, this care is often delivered with limited resources and stretched to capacity during 'normal' circumstances. Also, intensivists are able to predict where and why bottlenecks in patient management would occur since this is often a daily feature of their work. Finally, in the event that insufficient facility ICU resources are available, critical care will be provided in other non-ICU areas of the hospital. Who will provide this care? How will it be accomplished? What basic ICU skill sets should be taught to other hospital personnel? Deliberate planning around these issues must occur in hospitals and should be led by engaged critical care professionals.

\section{Why should intensivists be involved in disaster planning, education, and training?}

Disasters, whether natural or man-made, have always been part of human existence. Current evidence continues to support the threat of terrorism or of a man-made disaster occurring. Most emergency planning at the governmental level is on the basis of 'when' rather than 'if' and as such hospital planning must reflect this outlook [6].

A major incident plan should be based on local and regional facilities, incorporating experience gained from previous incidents and planning exercises. Planning in isolated 'silos' (as opposed to a more broadly considered systems-based approach) causes weaknesses that become all too apparent in the subsequent execution of a disaster response. Co- 
ordination of care as well as interoperability among the various work areas within the hospital will be hampered. And, unfortunately, most existing planning processes do not address necessary and essential critical care requirements.

Cooperation between designated receiving hospitals, neighbouring hospitals (which may be in competition with each other to provide local services), ambulance, police, and other rescue services is essential to ensure a structured and coordinated response. While it may seem difficult to plan at a local level for 'what may be', there are some questions that the intensivist must ask. Table 1 lists the questions we consider most important as a starting point in assessing and adapting our major incident planning.

We believe it essential that, in addition to involvement at the local level, all intensivists be acquainted with disaster response activation procedures as well as the roles and the responsibilities of various levels of command and control groups when disaster plans are activated.

Anaesthetists receive specific training in incident awareness which extends beyond clinical content, including the nonmedical aspects of high-performance team behaviours. Similarly, intensive care physicians should look upon their unique role in the provision of major incident care as an opportunity to develop the same skill sets [7].

\section{A circumspect view of the initial response Increasing capacity}

Experience has shown that bed capacity is often the ratelimiting step in caring for casualties [8]. This is especially true for intensive care beds since these are often running at, or close to, maximum capacity during normal daily hospital operations. The ability to successfully and safely expand and maintain surge capacity will depend on the following:

1. Type of disaster

2. Number of critically injured casualties

3. Duration of the casualty-generating circumstance

4. Available infrastructure (including staffing, equipment, and drugs and other consumables)

5. Quantity and duration of the enhanced critical care provision that is required.

On 7 July, there was an initial expectation to have to provide intensive care to a large number of casualties and increasing bed capacity was initiated with this in mind. In addition to the transfer of stable longer-term patients to neighbouring hospitals, patients on the ICU and surgical HDU who did not require inotropic or invasive ventilatory support were transferred to general wards, their care supported by the CCOT. The CCOT also supervised setting up a six-bed satellite ICU in the HDU. In addition, one of the recovery rooms was identified as a holding bay for patients prior to admission to the operating theatres and could also be used as another intensive care area. General ward areas were cleared and patients discharged to the community under the care of the primary health care system. Elective operating was suspended at the RLH as well as two nearby hospitals. Fortunately, the number of severely injured casualties admitted to the hospital was limited and these facilities were not required.

District general hospitals in our network area saw their casualty attendance rise as non-incident-related casualties diverted spontaneously. In the first hour after the bombings, the hospital switchboard received 25,000 additional calls, which rendered the internal phone system non-functional for the remainder of the day. The mobile phone networks were blocked at an early stage of the disaster to facilitate emergency service communication. Flexibility was required to use other resources (runners and internal email) to overcome the loss of these contact facilities. During this phase, the ongoing care of other (pre-event) critically ill patients required dedicated staff provisions in order to prevent attention being diverted exclusively to the disaster casualties.

The difficulty in planning was the uncertainty of when the flow of seriously injured casualties would stop. It was noted in the Madrid bombings of 2004 that the hospitals closest to the incidents were quickly overwhelmed [9]. This was not encountered in our situation, although more patients were triaged to our location due to its identifiable association with trauma management and the London Helicopter Emergency Medical Service.

Much emphasis has been placed on the 'command and control physician' in trauma resuscitation and this has been shown to enhance the performance of the trauma team $[10,11]$. In the intensive care setting, the intensivist should act as the conduit for all information flow regarding patient management decisions. This aspect of teamwork is liable to be put under pressure in disaster scenarios, especially highly emotionally charged situations, with the potential breakdown of the normal decision-making hierarchy.

On the day of the bombings, the senior nurse in the ICU became responsible for organising and dispatching runners to get updates, particularly from the operating theatre. A junior doctor was dedicated to compile work lists on a database as each patient was admitted, listing injuries, investigations, as well as current and planned treatment. This made planning subsequent care for each patient much clearer and smoother.

Multiple surgical teams were involved in patient care, and in subsequent days we found that teams made decisions without up-to-date knowledge regarding current patient status. The root cause of this shortcoming was the location of the handover meetings. We found it essential to centrally locate these multi-disciplinary meetings in the ICU itself rather than at a variety of distant locations. 


\section{Table 1}

\section{Pre-planning action list for intensive care unit and mass casualty events}

\section{Logistics}

Intensivist participates or is represented on the hospital major incident committee.

The major incident/disaster plan reflects the most likely events to be encountered, critical care elements are specifically addressed by the plan, and the plan is easily accessible.

Plans are rehearsed and reviewed at regular intervals to reflect changes in circumstances and new evidence. Additional training for key staff is required (clinical training as well as disaster response 'mechanics').

The plan contains provisions if decontamination and/or total intensive care unit (ICU) isolation becomes necessary.

Staging areas for staff, volunteers, and helpers are identified and practiced.

Are protocols in place for rationing (prioritisation) of ICU equipment if demand exceeds capacity (for example, mechanical ventilators)?

\section{Communication}

Up-to-date contact details are provided to all staff. Is this information easily accessible in an emergency?

Back-up communication systems when conventional systems are overwhelmed or fail are in place.

Liaison staff to deal with queries from relatives, the public, and media has been identified.

Links are established to inform local/regional back-up hospitals if we need help.

3. Capacity (including staffing)

How do we ensure that security (including checking of staff identity) is maintained?

Who is the lead intensivist and who is the senior nurse? Are their roles clearly defined?

What is the absolute limit in terms of increasing bed capacity? (This includes limits in terms of staffing.)

Transfer agreements with nearby intensive care units are in place.

How do we increase staffing, both clinical and non-clinical, and what is the fall-back position if this is not possible?

If the level of ICU care must be degraded because demand perniciously exceeds capacity, what is the plan to ensure that this occurs decrementally with defined priorities (as opposed to haphazardly)?

\section{Equipment}

Inventory and servicing of equipment are up to date (including back-up equipment).

What are our levels of supplies of consumables, and how do we rapidly increase delivery when there is a sudden increase in demand? How many supplies and doses of key medications do we have?

How do we cope with limitations in infrastructure (for example, power failure and communications failure)?

\section{Clinical triage}

Of immediate concern on the day of the explosions was that the hospital triage aligned patient needs with available resources. If an explosive-type disaster yields low numbers of critically injured patients, over-triage is likely to be a problem, with the attendant risk of increasing overall mortality [12]. On the day of the bombings, patients were triaged directly to the operating theatre by a senior surgeon who assigned a surgical 'team' (anaesthetist, surgeon, and operating department practitioner) to each of the patients to follow them from admission to the hospital through to the operating theatre and ultimately delivery into the ICU.

One of the early problems encountered was the identification of casualties. The standard triage system (casualty numbers assigned at the scene) did not 'dovetail' with our hospital's existing patient numbering system. Assigning additional hospital identifiers complicated cross-matching blood products, obtaining laboratory results, and requesting radiological imaging. The numbers assigned at the scene were not site-specific and caused initial problems in identifying victims. This experience is not unique and it has been suggested that separate documentation in such incidents be abandoned in favour of standard day-to-day paperwork [13].

The concept of 'damage control' resuscitation and surgery is not limited the operating theatre [14]. It is incumbent upon the ICU physician to become involved in a patient's care at the earliest opportunity. This means a presence in the resuscitation room. On the day of the bombings, there were three ICU physicians present in the emergency department who were directly involved in the resuscitation phase of the most seriously injured casualties. 


\section{Ongoing care}

While the casualty surge proved to be relatively brief and the hospital resources were able to accommodate all patients in a timely and appropriate fashion [12], this initial 24-hour burst of activity was just the start of a prolonged-care phase that greatly increased the surgical, anaesthetic, and intensive care workload.

As soon as the emergency department was cleared of casualties (within a few hours following the event), the major incident response was stood down. Within 5 hours of the start of the incident, the emergency department was reopened to major trauma casualties without necessarily considering the potential impact on the operating theatres (all working to maximal capacity). It is vitally important that these sorts of decisions be communicated and acknowledged at the managerial level and incorporated into the incident plan. (The seven patients admitted to the ICU arrived hours after the hospital major incident had been stood down.)

The haematology department at the RLH was one of the last to be informed that a major incident had occurred; this was identified as a weakness in the response to the incident at the time. In Israel, reliable access to blood for transfusion as part of the response to terrorist acts is seen as vital. This can ensure the blood supply in times of disasters and minimise outdating and wastage [15].

The timing of subsequent surgical intervention requires a combined surgical, anaesthetic, and intensive care approach. Recent evidence suggests that the inflammatory response to multiple trauma can be exacerbated by surgery that extends beyond the remit of damage control in the early stages [16].

To facilitate the number of complex admissions, we increased the number of senior staff working the 24 hours, with a rotational system of senior staff to spread the workload. It proved difficult for all concerned to retain focus on the care of the other ICU patients and we formally divided duties to maintain consistent patient care to all.

Beyond the initial crisis, there is a need for longer-term planning as recovery from critical care can take weeks and months. Where extensive physical injuries are involved, multiple surgical procedures often are followed by intensive and sometimes prolonged rehabilitation. The lessons learned in Australia and Israel can prove useful in guiding requirements in this phase of care $[17,18]$.

\section{Reflection and debriefing}

The problems we faced following the events of July 2005 were not unique and are seen on an ongoing basis in other parts of the world, including settings of insurgency warfare, such as in Iraq and Afghanistan [19,20]. Even with a comprehensive major incident plan and daily experience of multi-trauma patient management, there still were some obvious deficiencies in our system. The ethical dilemma of 'non-clinical' transfers is an uncomfortable aspect of increasing capacity which needs to be considered and agreed upon in advance. Not all of these were initially apparent and it took more than 6 months to collate data. A dedicated hospital-wide audit also brought the various teams together to get a broad base of learning points. Intensive care services have an important position in relation to these types of casualties and our major incident plan had to be revised and extended to include bioterrorism and infectious disease strategies $[21,22]$. The detonations occurred in the relative confines of underground train carriages and tunnels and in a bus. The initial management focused on the basics of intensive care, achieving optimal oxygenation and perfusion, with a shift in individual patient management dependent on the injury profile $[23,24]$. Bedside toxicology and chemical agent monitors should be available in the ICU setting to screen for the possibility of exposure. The extent of our normal daily emergency workload as a major trauma receiving centre, combined with a reasonable major incident plan and the flexibility of all members of staff, were also major contributory factors. The ability to provide best-practice care without compromise probably contributed to our low mortality. The long-term psychological impact of a terrorist act should not be underestimated. Communication with psychological support staff at an early stage is essential to ensure that patients, relatives, and staff can be advised of how to access these services, should they be required [25].

\section{Suggested next steps}

A detailed risk assessment for specific crisis scenarios is helpful, but trying to 'best guess' the next incident could detract from robust flexible planning. Abortive terrorist attacks in London and Glasgow in July 2007 have served to emphasise the ongoing threat in the UK. Worldwide, ongoing terrorist activities, natural disasters, and the threat of a flu pandemic all serve to highlight the need for comprehensive planning strategies. Each major incident plan is only as good as the last time it was implemented. In crisis situations, evidenced-based medical practice can all too easily be replaced by panic, chaos, and emotionally based responses. To minimise this, robust planning is of the essence and intensivists should be involved in disaster planning at each hospital level from admission to discharge.

Preparedness requires meticulous planning, extensive education, and regular rehearsal and review if it is to be effective. Even though major incident planning is recognised as a priority for hospitals, many are still struggling to implement changes to result in tangible improvements. Medical and nursing staff can turn over at a high rate and because of this it has been suggested that more standardisation between hospitals in incident planning occur. It is also incumbent on all staff to take the initiative to find out their unit's major incident plan and familiarise themselves with their indicated roles [26]. Many American hospitals, in light of events surrounding the 
Table 2

\section{Suggested action card for the intensive care unit physician}

Action card - intensive care unit (ICU) physician

Initial actions

- Make contact with the incident medical director (emergency department consultant).

- Check details of the incident.

- Assess the need for ICU beds and the timeframe.

- Liase with the senior ICU nurse and identify potential increases in capacity.

- Liase with the senior anaesthetist and senior surgeon.

- Consider the level of response required and identify staffing.

- Establish the need for satellite ICU/high-dependency unit beds or other beds.

- Ensure a sufficient number of runners to relay information on patient movements.

- Establish an ICU control room with updates.

Clinical care

- Identify current patients suitable for transfer.

- Designate senior ICU medical representation for the resuscitation room.

- Identify likely ICU patients and their dispersal (theatres, computed tomography, or direct admissions).

- Ensure that care is not compromised in existing non-incident ICU patients.

- In the event that resources are overwhelmed, liase with other senior clinicians about the diverting of patients.

Post-incident

- Identify pitfalls in planning early and address them at the earliest opportunity.

- Ensure the ongoing welfare and support of staff, patients, and relatives.

attacks of 11 September 2001 and Hurricane Katrina in 2005 , have issued very clear guidance in regard to the 'commandments' of major incident plans [27]. We feel it is important that the ICU physician have a specific action card within the hospital disaster plan, and at the RLH we are trying to incorporate this into the major incident planning. Our suggested example is shown in Table 2.

\section{Conclusion}

The provision of robust effective critical care along with ICU functionality (efficiency) are vital parts of effective disaster medical response. Lessons learned from the London bombings by our hospital underscore the necessity of intensivists in the planning as well as execution phases of disaster medical response. We believe that these principles are broadly applicable to all types of disasters.
This article is part of a review series on Disaster management, edited by J Christopher Farmer.

Other articles in the series can be found online at http://ccforum.com/articles/ theme-series.asp?series=CC_Disaster

\section{Competing interests}

The authors declare that they have no competing interests.

\section{References}

1. Lavery G, Horan E: Clinical review: communication and logistics in the response to the 1998 terrorist bombing in Omagh, Northern Ireland. Crit Care 2005, 9:401-408.

2. Hawryluck L, Lapinsky SE, Stewart TE: Clinical review: SARS lessons in disaster management. Crit Care 2005, 9:384-389.

3. Mohammed AB, Mann HA Nawabi DH, Goodier DW, Ang SC: Impact of London's terrorist attacks on a major trauma centre in London. Prehosp Disast Med 2006, 21:340-344.

4. Avidan V, Hersch M, Spira RM, Einav S, Goldberg S, Schecter W: Civilian hospital response to a mass casualty event: the role of the intensive care unit. J Trauma 2007, 62:1234-1239.

5. Roccaforte JD, Cushman JG: Disaster preparation and management for the intensive care unit. Curr Opin Crit Care 2002, 8:607-615.

6. Frykberg ER: Medical management of disasters and mass casualties from terrorist bombings: how can we cope? Trauma 2002, 53:201-212.

7. Fletcher G, Flin R, McGeorge P, Glavin R, Maran N, Patey R: Anaesthetists' Non-Technical Skills (ANTS): evaluation of a behavioural marker system. Br J Anaesth 2003, 90:580-588.

8. Johannigman JA: Disaster preparedness: it's all about me. Crit Care Med 2005, 33:S22-S28.

9. Gutierrez de Ceballos JP, Turégano Fuentes F, Perez Diaz D Sanz Sanchez M, Martin Llorente C, Guerrero Sanz JE: Casualties treated at the closest hospital in the Madrid, March 11, terrorist bombings. Crit Care Med 2005, 33:S107-S112.

10. Hoff WS, Reilly PM, Rotondo MF, DiGicomo CJ, Schwab WC: The importance of the command physician in trauma resuscitation. J Trauma 1997, 43:772-777.

11. Thomas TL, Hsu EB, Kim HK, Colli S, Arana G, Green GB: The incident command system in disasters: evaluation methods for a hospital based exercise. Prehosp Disast Med 2005, 20: 14-23.

12. Aylwin CJ, Konig TC, Brennan NW, Shirley PJ, Davies G, Walsh MS, Brohi K: Reducing critical mortality in urban mass casualty incidents: analysis of triage, surge and resource use after the London bombings on July 7, 2005. Lancet 2006, 368:22192225

13. Nocera A, Garner A: An Australian mass casualty incident triage system for the future based upon triage mistakes of the past: the homebush triage standard. Aust N Z J Surg 1999, 69:603-608.

14. Sagraves SG, Toschlog EA, Rotondo MF: Damage control surgery-the intensivist's role. J Intensive Care Med 2006, 21: 5-16.

15. Shinara E, Yahaloma V, Silverman BG: Meeting blood requirements following terrorist attacks: the Israeli experience. Curr Opin Hematol 2006, 13:452-456.

16. Tschoeke SK, Hellmuth M, Hostmann A, Ertel W, Oberholzer A: The early second hit in trauma management augments the pro-inflammatory immune response to multiple injuries. $J$ Trauma 2007, 62:1396-1404.

17. Rosenfeld JV, Fitzgerald M, Kossmann T, Pearce A, Joseph A, Tan G, Gardner M, Shapira S: Is the Australian hospital system adequately prepared for terrorism? Med J Aust 2005, 183: 567-570.

18. Aschkenasy-Steuer G, Shamir M, Rivkind A, Mosheiff R, Shushan Y, Rosenthal G, Mintz Y, Weissman C, Sprung CL, Weiss YG: 
Clinical review: The Israeli experience: conventional terrorism and critical care. Crit Care 2005, 9:490-499.

19. Gawande A: Casualties of war-military care for the wounded from Iraq and Afghanistan. N Engl J Med 2004, 351:24712475.

20. Eiseman, B; Chandler JG: Military medical surge capacity in times of war and natural disaster. J Trauma 2006, 60:237-239.

21. White SM: Chemical and biological weapons. Implications for anaesthesia and intensive care. $\mathrm{Br} J$ Anaes 2002, 89:306-324.

22. Baker DJ: Critical care requirements after a mass toxic agent release. Crit Care Med 2005, 33:S66-S74.

23. Levi L, Michaelson M, Admi H, Bregman D, Bar-Nahor R: National strategy for mass casualty situations and its effects on the hospital. Prehosp Disast Med 2002, 17:12-16.

24. Singer $\mathrm{P}$, Cohen JD, Stein M: Conventional terrorism and critical care. Crit Care Med 2005, 33:S61-S65.

25. Wessely S: The London attacks-aftermath: Victimhood and resilience. N Engl J Med 2005, 353:548-550.

26. Wong K, Turner PS, Boppana A, Nugent Z, Coltman T, Cosker TD, Blagg SE: Preparation for the next major incident: are we ready? Emerg Med J 2006, 23:709-712.

27. Lynn M, Daniel D, Memon A, Kaliff J: Management of conventional mass casualty incidents: ten commandments for hospital planning. J Burn Care Res 2006, 27:649-658. 